\title{
Treatment Strategies for the Behavioral Symptoms of Alzheimer's Disease: Focus on Early Pharmacologic Intervention
}

\begin{abstract}
Manju T. Beier, Pharm.D., FASCP
The impact of behavioral symptoms associated with Alzheimer's disease is substantial. These symptoms contribute to diminished quality of life for patients and caregivers and increase the cost of care in nursing homes. Early recognition of behavioral symptoms and appropriate treatment are important for successful management. Nonpharmacologic strategies remain the cornerstone of the management of Alzheimer's disease-related behavioral symptoms. However, nonpharmacologic strategies may not be effective for problem behaviors, and pharmacologic intervention may be necessary. Relevant articles were identified through various MEDLINE searches with no date restrictions, with an emphasis on recent studies that used cholinesterase inhibitors and memantine. Additional reports of interest were identified from the reference lists of these articles. To facilitate cross-study analyses in the review of cholinesterase inhibitors and memantine, the database search was limited to randomized, placebo-controlled trials that used the Neuropsychiatric Inventory to assess behavioral symptoms of Alzheimer's disease. Overall, evidence from trials of cholinesterase inhibitors and memantine suggests that when these agents are optimized for the various stages of Alzheimer's disease, they can also prevent the emergence of neuropsychiatric symptoms. Although results from the literature are not uniformly positive, cholinesterase inhibitors have been shown to produce significant improvements in behavioral symptoms in patients with both mildto-moderate and moderate-to-severe Alzheimer's disease. Evidence also indicates that memantine might be of benefit as an adjunct to long-term cholinesterase inhibitor treatment in patients with moderate-to-severe Alzheimer's disease and that memantine monotherapy may have some beneficial effects on behavior in patients with mild-to-moderate disease. Of importance, although no direct comparisons have been performed, these agents seem to have an improved safety and tolerability profile compared with the frequently used antipsychotic drugs. When nonpharmacologic strategies are deemed insufficient to ease problem behaviors in patients with Alzheimer's disease, treatment with cholinesterase inhibitors, alone or in combination with memantine as appropriate for the stage of disease, may be considered as a first-line option in the early pharmacologic management of Alzheimer's disease-related behavioral symptoms.
\end{abstract}

Key Words: Neuropsychiatric Inventory, Alzheimer's disease, behavior, cholinesterase inhibitors, memantine.

(Pharmacotherapy 2007;27(3):399-411) 


\section{OUTLINE}

Nonpharmacologic Management of Behavioral Symptoms

Pharmacologic Management of Behavioral Symptoms Literature Review Methodology

Cholinesterase Inhibitors

Memantine

Other Pharmacologic Treatments

Discussion

Conclusion

Alzheimer's disease is a degenerative brain disorder that causes cognitive decline, loss of function, and emergence of behavioral or neuropsychiatric symptoms. ${ }^{1}$ It is the most common cause of dementia in the United States, affecting about 4.5 million Americans in 2000, ${ }^{2}$ and is most prevalent in the elderly, occurring in $3 \%$ of the population aged $65-74$ years, $19 \%$ of the population aged $75-84$ years, and in almost $50 \%$ of seniors aged 85 years or older. ${ }^{3}$ Alzheimer's disease is particularly common among nursing home residents, with more than half of those aged 65 years or older having Alzheimer's disease or related dementias. ${ }^{4}$

Alzheimer's disease follows a predictable course that usually begins with memory loss. As the disease progresses, cognitive impairment becomes profound and daily functioning skills decline. Although typically thought of as indicative of late-stage disease, behavioral symptoms can appear early in the course of the disease, well before clinical diagnosis. These symptoms can include social withdrawal, depression, paranoia, and mood changes. ${ }^{5} \mathrm{~A}$ study of the natural history of Alzheimer's disease showed that $53 \%$ of patients demonstrated symptoms of depression an average of 26 months before diagnosis (Figure 1). ${ }^{5}$ As the disease advances, symptoms such as anxiety, irritability, and agitation become more pronounced. Nearly 90\% of patients with Alzheimer's disease develop behavioral symptoms during their illness ${ }^{6}$; as many as $40 \%$ have symptoms of mild depression, and up to $66 \%$ experience anxiety. ${ }^{7}$

From the College of Pharmacy, University of Michigan, and Geriatric Consultant Resources LLC, Ann Arbor, Michigan.

Dr. Beier has received speaker honoraria from and has served as a consultant for Forest Pharmaceuticals, St. Louis, Missouri, Pfizer Inc., New York, New York, and Eisai Inc., Teaneck, New Jersey.

Address reprint requests to Manju T. Beier, Pharm.D., FASCP, Geriatric Consultant Resources LLC, 2001 Commonwealth Boulevard, Suite 205, University of Michigan, Ann Arbor, MI 48105; e-mail: tanja@umich.edu.
The behavioral aspects of Alzheimer's disease are highly distressing for the patient. Symptoms of agitation (including inappropriate motor activity), apathy, and psychosis (e.g., hallucinations) are common and are exacerbated in the presence of the patient's existing disabilities. Behavioral symptoms further erode independence and engender feelings of fear, anger, and frustration. In a survey of patients with Alzheimer's disease in residential care in the United Kingdom, loss of self-esteem and feelings of fear, bewilderment, and frustration contributed to depression and withdrawal. ${ }^{8}$ More distressing symptoms, such as agitation, violence, incontinence, and wandering, often prompt nursing home placement. ${ }^{9}$

Behavioral symptoms are also a major source of stress for the caregiver. Behavioral disturbances have been shown to be a strong predictor of caregiver burden ${ }^{10}$ and are associated with increased financial hardship for the caregiver (e.g., loss of income, out-of-pocket expenses for formal health care or excess costs related to the caregivers' health problems). ${ }^{11}$ Indeed, caregivers of patients with Alzheimer's disease often consider behavioral and psychiatric symptoms to be the most challenging and distressing aspects of the disease. ${ }^{12}$

\section{Nonpharmacologic Management of Behavioral Symptoms}

Nonpharmacologic interventions have the potential to reduce the frequency and severity of behavioral symptoms in patients with dementia who reside in nursing homes. ${ }^{13-26}$ Although the choice of technique depends on the target behavioral symptom, nonpharmacologic techniques target three broad problems: behaviors caused by unmet patient needs, those caused by

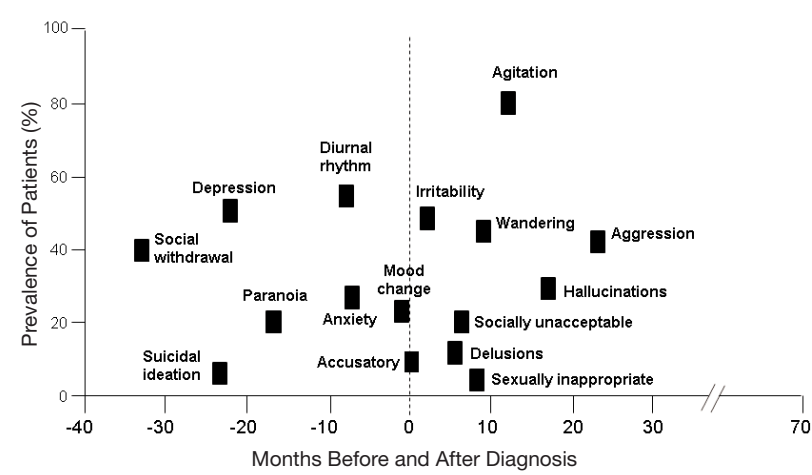

Figure 1. Onset of behavioral symptoms of Alzheimer's disease relative to time of diagnosis. (From reference 5.) 
Table 1. Nonpharmacologic Interventions for Behavioral Symptoms of Alzheimer's Disease

\begin{tabular}{|c|c|}
\hline Intervention Type & Outcome \\
\hline $\begin{array}{l}\text { Sensory stimulation } \\
\text { Music therapy }{ }^{16,18} \\
\text { Touch therapy (e.g., massage) })^{16,20} \\
\text { Bright-light therapy }^{16,21}\end{array}$ & $\begin{array}{l}\text { Evidence exists that aural and physical stimulation } \\
\text { can significantly reduce agitation and aggression. } \\
\text { Light therapy may aid sleep disorders and lessen } \\
\text { severity of sundowning. }^{\text {a }}\end{array}$ \\
\hline $\begin{array}{l}\text { Social contact } \\
\text { One-to-one contact } \mathrm{t}^{15} \\
\text { Pet therapy } 14,16 \\
\text { Simulated presence therapy (audio or } \\
\text { video of family) }\end{array}$ & $\begin{array}{l}\text { Real or simulated social contact can decrease verbal } \\
\text { agitation, aggression, and other disruptive behaviors; } \\
\text { in some studies, effect reached statistical significance. }\end{array}$ \\
\hline $\begin{array}{l}\text { Environment } \\
\text { Ensure environment is safe (remove sharp } \\
\text { edges, install safety locks and grab bars) } \\
\text { Do not overstimulate patients (reduce glare } \\
\text { and noise) }\end{array}$ & $\begin{array}{l}\text { Environmental intervention can decrease verbal and } \\
\text { physical aggression; may reduce wandering or pacing }\end{array}$ \\
\hline $\begin{array}{l}\text { Orientation } \\
\text { Maintain a daily routine }{ }^{17,24} \\
\text { Allow patient independence (wash and dress } \\
\text { themselves, keep personal possessions) } \\
\text { Simplify all tasks (give instructions, complex } \\
\text { tasks should be attempted in stages) } \\
\text { Provide calendars, clocks, and newspapers } \\
\text { to orient time } \\
\text { Distract and redirect patients as needed } \\
\text { Remove physical restraints }^{16}\end{array}$ & $\begin{array}{l}\text { Orientation intervention can significantly increase } \\
\text { nondependency in activities of daily living and } \\
\text { promotes independence; can also reduce disruptive } \\
\text { behavioral symptoms. }\end{array}$ \\
\hline $\begin{array}{l}\text { Recreation } \\
\text { Exercise programs }{ }^{22} \\
\text { Walking }^{19,24} \\
\text { Sorting } \\
\text { Group activities, games, and singing } \\
\text { G, } 25\end{array}$ & $\begin{array}{l}\text { Recreation can decrease agitation and aggression; } \\
\text { in some studies, effect reached statistical significance. }\end{array}$ \\
\hline
\end{tabular}

aggravating factors, and those caused by ill-suited environments. ${ }^{16}$ For example, removing any medical causes of problem behaviors (e.g., pain and delirium), reducing any excess stimulation in the environment, and eliminating any known triggers may reduce physical and verbal aggression. Use of nonpharmacologic techniques to manage behaviors in the nursing home helps physicians, pharmacists, nurses, and staff begin to view behaviors as symptoms of underlying medical and environmental problems. A group of authors showed that implementation of an education program that trained providers (e.g., nursing home staff, physicians, nurses, nursing assistants, and other direct care staff) in the use of structured guidelines to improve the management of behavioral problems and to minimize the use of antipsychotic drugs reduced the number of days of antipsychotic drug use by $72 \%$, with no increase in behavioral symptom frequency. ${ }^{27}$ Therefore, nonpharmacologic strategies can have meaningful benefits, such as a reduced need for psychotropic drugs. Table 1 summarizes some of the commonly used nonpharmacologic techniques and their associated outcomes. Several small studies have shown the often significant benefits of nonpharmacologic interventions, such as music therapy, ${ }^{16,18}$ massage or aromatherapy, ${ }^{16,20}$ and pet therapy. ${ }^{14,16}$

The current limitations in our understanding of the effectiveness of nonpharmacologic therapies for the management of behavioral systems in patients with Alzheimer's disease result from difficulties in recruiting patients for large-scale, randomized studies of these treatments. This is generally due to reluctance of caregivers and/or nursing home personnel, problems with implementation of treatments resulting from limitations in communication with patients, and insufficient funding. ${ }^{16}$ Despite these limitations, nonpharmacologic interventions are the preferred first step in the management of behavioral symptoms. However, these approaches are not always completely effective. When this is the case, pharmacologic therapy should be considered. 


\section{Pharmacologic Management of Behavioral Symptoms}

The neurobiologic basis for the effects of cholinesterase inhibitors and memantine on the behavioral symptoms of Alzheimer's disease remains unclear. Nevertheless, studies have alluded to potential substrates for some of the emotional disturbances of Alzheimer's disease and their response to cholinesterase inhibitors. For example, dysfunctions in the limbic and paralimbic cortices have been associated with various neuropsychiatric disturbances in patients with Alzheimer's disease. ${ }^{28}$ Moreover, atrophy of the occipital lobe has been associated with visual hallucinations ${ }^{29}$; hypoperfusion of the frontal and temporal regions has been linked to apathy, delusions, and aggression ${ }^{30-32}$; and hypoperfusion of the orbitofrontal cortex has been related to apathy, disinhibition, irritability, and euphoria. ${ }^{33,34}$ In addition, similarities between the neuropsychiatric symptoms of Alzheimer's disease and anticholinergic toxicity, as well as the reported anatomic distribution of cholinergic deficits in patients with Alzheimer's disease, link cholinergic abnormalities to behavioral disturbances. ${ }^{35}$ Specific studies, of course, are required to elucidate the precise mode of action whereby cholinesterase inhibitors affect behavior. However, it could be postulated that through their ability to ameliorate cholinergic deficits and/or stabilize or increase cerebral blood flow, ${ }^{36-38}$ cholinesterase inhibitors might facilitate changes that positively affect behavior in patients with Alzheimer's disease.

Similarly, reports demonstrating that glucose metabolism is altered in the frontal, parietal, and/or temporal lobes of patients with Alzheimer's disease who experience agitation, anxiety, or delusions, ${ }^{39,}{ }^{40}$ might suggest hypothetic targets for the effect of memantine on behavior. Again, dedicated studies are needed to determine the specific mechanisms involved in the effects of memantine on the behavioral symptoms of Alzheimer's disease.

\section{Literature Review Methodology}

Randomized, placebo-controlled clinical trials that evaluated the effectiveness of cholinesterase inhibitors and/or memantine for the treatment of Alzheimer's disease-related behavioral symptoms were identified using the following methods. MEDLINE searches were carried out using the terms Alzheimer's or Alzheimer, and neuropsychiatric or NPI or Neuropsychiatric
Inventory, with no date restrictions. Abstracts or, where necessary, complete articles were reviewed to determine whether the study used a cholinesterase inhibitor and/or memantine for treatment and whether the Neuropsychiatric Inventory was used to evaluate symptoms. Other reports and abstracts of interest, which used the Neuropsychiatric Inventory, were identified from the reference lists of these articles. The literature search was current as of August 2006. As this review did not constitute a formal meta-analysis of the data, no assessments for the possible effect of publication bias were performed.

Restricting the review of cholinesterase inhibitors and memantine to trials that used the Neuropsychiatric Inventory was necessary to allow analysis of efficacy across different studies. The Neuropsychiatric Inventory is a specific measure for the frequency and severity of neuropsychiatric or behavioral symptoms associated with Alzheimer's disease. The original 10-item Neuropsychiatric Inventory assesses delusions, hallucinations, agitation/aggression, depression/dysphoria, anxiety, euphoria/elation, apathy/indifference, disinhibition, irritability/ lability, and aberrant motor behavior, with each item being scored from 0-12. ${ }^{41}$ A 12-item version, specifically modified for nursing home residents and called the Neuropsychiatric Inventory Nursing Home version or Neuropsychiatric Inventory- $\mathrm{NH}$, is also commonly used, and assesses all of the above items with the addition of nighttime behavior and appetite or eating disorders. ${ }^{42,43}$ The total score ranges for the 10-item Neuropsychiatric Inventory and 12item Neuropsychiatric Inventory-NH are 0-120 and $0-144$, respectively, with higher scores indicating greater behavioral impairment.

To put the Neuropsychiatric Inventory scale into the context of this article, a study of behavioral changes in patients with Alzheimer's disease showed a mean total 10-item Neuropsychiatric Inventory score of 9.8 for mild Alzheimer's disease (Mini-Mental State Examination [MMSE] score 21-30), 14.7 for moderate Alzheimer's disease (MMSE score 11-20), and 21.9 for severe Alzheimer's disease (MMSE 0-10) among their enrolled patients. ${ }^{6}$ At present, it is still unclear how much of an absolute change in Neuropsychiatric Inventory score constitutes a clinically meaningful improvement. As a result, for each randomized, placebo-controlled study reviewed, the baseline Neuropsychiatric Inventory score has been reported to allow interpretation of the change 
from baseline.

Although the approach used for selection of trials included in this review of cholinesterase inhibitors and/or memantine was aimed at facilitating comparison of results obtained with different drugs, it must be acknowledged that differences in the design and reporting of findings in different studies still limits such comparisons. One group of authors recently reviewed limitations in the design and reporting of results in all controlled clinical trials of cholinesterase inhibitors for patients with Alzheimer's disease. ${ }^{44}$ Many of the studies reviewed in this review article were also evaluated by these investigators. Although a detailed analysis of the study design, data analysis, and approaches to reporting of results is beyond the scope of this review, it is nevertheless important to caution readers about the limitations of comparing different drugs without the benefit of results from direct head-to-head comparison studies.

\section{Cholinesterase Inhibitors}

The cholinesterase inhibitors-donepezil, galantamine, and rivastigmine-are all approved by the United States Food and Drug Administration (FDA) for the treatment of mildto-moderate Alzheimer's disease and are recommended as first-line treatment for patients in these stages of the disease. ${ }^{45}$ In clinical trials, these agents have been shown to positively affect the cognitive and functional symptoms of Alzheimer's disease and can also provide behavioral benefits to patients with this disease. ${ }^{46-55}$ Indeed, a recent review of the pharmacologic treatment of behavioral symptoms in dementia (including vascular and Lewy body dementia) with cholinesterase inhibitors indicated that most studies reported small, but statistically significant, benefits on behavioral symptoms. ${ }^{56}$

\section{Mild-to-Moderate Alzheimer's Disease}

Randomized, placebo-controlled clinical studies that used the Neuropsychiatric Inventory to assess the effects of cholinesterase inhibitors on behavior in patients with mild-to-moderate Alzheimer's disease have been published for donepezil and galantamine, ${ }^{49,53,54}$ but not for rivastigmine. In the donepezil study, patients received donepezil for 12 weeks in the open-label phase; they were then randomly assigned to receive either donepezil $10 \mathrm{mg} /$ day or placebo for an additional 12 weeks. ${ }^{49}$ In the open-label phase, a significant decrease was noted in total Neuropsychiatric Inventory scores at weeks 6 and 12 compared with baseline $(\mathrm{p}<0.0001)$. At week 12, all of the individual behavioral symptoms, including agitation, anxiety, apathy, depression, and delusions, had significantly improved compared with baseline $(p<0.005)$, with the exception of elation. Patients who received donepezil after randomization (weeks 12-24) continued to improve, whereas those patients receiving placebo had a worsening of behavioral symptoms, leading to an absolute treatment difference of 6.2 points by week 24 (treatment difference $\mathrm{p}=0.02$; Table 2). Caregiver distress associated with behavioral symptoms also worsened in caregivers of placebo-treated patients during weeks 12-24, but improved in caregivers of patients treated with donepezil (treatment difference $\mathrm{p}=0.01$ ).

The efficacy of galantamine in reducing behavioral symptoms in patients with mild-tomoderate Alzheimer's disease was evaluated in two randomized, placebo-controlled clinical trials. $^{53,54}$ The first assessed the efficacy of 5 months of treatment with three doses of galantamine $\left(8,16\right.$, and $24 \mathrm{mg}$ /day) or placebo. ${ }^{53}$ After 5 months, Neuropsychiatric Inventory scores remained at baseline severity in patients who received treatment with galantamine either 16 or $24 \mathrm{mg} /$ day, but increased from baseline in patients receiving the lowest dose of $8 \mathrm{mg} /$ day (mean +2.3 points) or placebo (mean +2.0 points). In the other trial, a 3-month flexibledose study, neither galantamine 24 or $32 \mathrm{mg}$ /day nor placebo resulted in a substantial change from baseline in Neuropsychiatric Inventory scores. ${ }^{54}$ That no effect on behavior was seen in the latter trial was likely due to the short study duration and the exclusion of patients with behavioral problems at baseline.

Recently, the effectiveness of donepezil and galantamine for treating problem behaviors was directly compared over 52 weeks in patients with mild-to-moderate Alzheimer's disease. ${ }^{61}$ Although the effect on behavioral symptoms was a secondary outcome of the study, and no data were presented in the published article, the authors stated that assessment of the mean change in Neuropsychiatric Inventory demonstrated no significant difference from baseline between groups at end point. Of interest, in another long-term study assessing the efficacy of donepezil for up to 4 years in patients with mildto-moderate Alzheimer's disease, no significant differences were observed in mean Neuropsychiatric 
Table 2. Efficacy of Cholinesterase Inhibitors and Memantine on the Behavioral Symptoms of Patients with Alzheimer's Disease: Results from Randomized, Placebo-Controlled Trials That Used the Neuropsychiatric Inventory Scale

\begin{tabular}{|c|c|c|c|c|c|c|}
\hline & Study & & & Maximum & Mean Basel & NPI Score \\
\hline Drug & $\begin{array}{l}\text { Duration } \\
\quad(\mathrm{mo})\end{array}$ & Disease Stage & $\begin{array}{c}\text { Baseline } \\
\text { MMSE Score }\end{array}$ & $\begin{array}{l}\text { Dosage } \\
\text { (mg/day) }\end{array}$ & $\begin{array}{l}\text { Treatment } \\
\text { Group }\end{array}$ & $\begin{array}{l}\text { Placebo } \\
\text { Group }\end{array}$ \\
\hline $\begin{array}{l}\text { Cholinesterase } \\
\text { inhibitors }\end{array}$ & & & & & & \\
\hline Donepezil ${ }^{49}$ & $6^{c}$ & Mild to moderate & $10-27$ & 10 & 14.3 & 15.1 \\
\hline Galantamine $e^{53}$ & 5 & Mild to moderate & $10-22$ & $\begin{array}{l}16 \\
24\end{array}$ & $\begin{array}{l}12.4 \\
11.9\end{array}$ & 11.0 \\
\hline Donepezil $^{47}$ & 6 & Moderate to severe & $5-17$ & 10 & 19.6 & 19.3 \\
\hline Donepezil ${ }^{43}$ & 6 & $\begin{array}{l}\text { Mild to severe; } \\
\text { nursing home study }\end{array}$ & $5-26$ & 10 & 21.0 & 20.5 \\
\hline Donepezil $^{57}$ & 6 & Severe; nursing home study & $1-10$ & 10 & 19.0 & 19.6 \\
\hline $\begin{array}{l}\text { Memantine } \\
\text { Memantine }\end{array}$ & 6 & Mild to moderate & $10-22$ & 20 & 11.5 & 122 \\
\hline $\begin{array}{l}\text { Donepezil + } \\
\text { memantine }\end{array}$ & 6 & Moderate to severe & $5-14$ & 20 & 13.4 & 13.4 \\
\hline Memantine $^{60}$ & 7 & Moderate to severe & $3-14$ & 20 & 21.4 & 19.5 \\
\hline $\begin{array}{l}\text { MMSE = Mini-Me } \\
\text { significantly differe } \\
\text { aValue shown repre } \\
{ }^{b} \mathrm{p} \text { value is for comp } \\
\text { cThree months ope } \\
\text { score shown is scor } \\
\text { din favor of placebo }\end{array}$ & $\begin{array}{l}\text { State Exa } \\
\text { its mean ch } \\
\text { ison of mea } \\
\text { label treatm } \\
\text { t randomiza }\end{array}$ & $\begin{array}{l}\text { ation; NPI = Neuropsychiatric } \\
\text { from baseline; SEM values are g } \\
\text { nge from baseline for treatment } \\
\text { vith donepezil, then randomiza } \\
\text { (i.e., after } 3 \text { mo of open-label do }\end{array}$ & $\begin{array}{l}\text { Iventory; SEN } \\
\text { n when availa } \\
\text { d placebo gro } \\
\text { n to receive e } \\
\text { pezil). }\end{array}$ & dondard erro & $\begin{array}{l}\text { udy. } \\
\text { bo for } 3 \mathrm{mo}\end{array}$ & Baselir \\
\hline
\end{tabular}

Inventory changes between treated patients and those receiving placebo. ${ }^{62}$ However, there are concerns regarding the validity of these data, as the study was underpowered, had very high attrition rates ( $80 \%$ by the end of year 2 ), and was designed to include multiple drug washout periods. ${ }^{63}$

Results from a meta-analysis of randomized, placebo-controlled trials investigating the functional and behavioral effects of several cholinesterase inhibitors in patients with mild-tomoderate Alzheimer's disease were recently published. ${ }^{64}$ Six of the 29 trials included in the overall meta-analysis used the Neuropsychiatric Inventory to measure neuropsychiatric outcomes: two galantamine trials (978 and 386 patients, trial durations 150 and 90 days), one donepezil trial (286 patients, trial duration 365 days), and three trials of a newer cholinesterase inhibitor, metrifonate $(408,605$, and 264 patients, trial durations 168, 168, and 182 days). (Metrifonate has now been removed from development due to toxicity issues.) For these six trials, summary meta-analysis showed a small but statistically significant difference of 1.72 points compared with placebo $(95 \%$ confidence interval $0.87-2.57$ ). As a result, the authors concluded that for patients with mild-to-moderate
Alzheimer's disease who have neuropsychiatric symptoms, cholinesterase inhibitors should be considered as a first-line therapeutic option. ${ }^{64}$

\section{Moderate-to-Severe Alzheimer's Disease}

At present, donepezil is the only cholinesterase inhibitor approved by the FDA for the treatment of severe Alzheimer's disease. The efficacy and safety of donepezil have been assessed in a randomized, placebo-controlled study of patients with moderate-to-severe Alzheimer's disease that used the Neuropsychiatric Inventory to assess behavioral symptoms (Table 2). ${ }^{47}$ In this trial, total Neuropsychiatric Inventory scores were improved from baseline by 4.6 points after 6 months of treatment, whereas those in the placebo group worsened by 1 point (treatment difference $\mathrm{p}=0.0005$ ). Significant improvements favoring donepezil were seen in the symptoms of apathy, depression/dysphoria, and anxiety.

\section{Patients in Nursing Homes}

To our knowledge, donepezil is the only cholinesterase inhibitor to have been studied in prospective, placebo-controlled trials in patients in nursing homes that used the Neuropsychiatric Inventory or Neuropsychiatric Inventory-NH as 
Table 2. (continued)

\begin{tabular}{|c|c|c|c|}
\hline \multicolumn{4}{|c|}{ Mean \pm SEM Change in NPI Score ${ }^{a}$} \\
\hline $\begin{array}{l}\text { Treatment } \\
\text { Group }\end{array}$ & $\begin{array}{l}\text { Placebo } \\
\text { Group }\end{array}$ & $\mathrm{p}$ Value $^{\mathrm{b}}$ & $\begin{array}{l}\text { Treatment } \\
\text { Difference }\end{array}$ \\
\hline$-2.9 \pm 1.6$ & $+3.3 \pm 2.1$ & 0.02 & 6.2 \\
\hline $\begin{aligned}-0.1 & \pm 0.7 \\
0.0 & \pm 0.8\end{aligned}$ & $+2.0 \pm 0.7$ & $\begin{array}{l}<0.05 \\
<0.05\end{array}$ & $\begin{array}{l}2.1 \\
2.0\end{array}$ \\
\hline-4.6 & +1.0 & 0.0005 & 5.6 \\
\hline$-2.3 \pm 1.9$ & $-4.9 \pm 1.9$ & NS & $2.6^{\mathrm{d}}$ \\
\hline$-3.2 \pm 1.3$ & $-1.7 \pm 1.4$ & NS & 1.5 \\
\hline-1.4 & +2.1 & 0.011 & 3.5 \\
\hline$-0.1 \pm 0.98$ & $+3.7 \pm 0.99$ & 0.002 & 3.8 \\
\hline+0.5 & +3.8 & NS & 3.3 \\
\hline
\end{tabular}

an outcome measure (Table 2). ${ }^{43,57}$ In the first study, patients in all stages of Alzheimer's disease were included (MMSE scores of 5-26), and concomitant psychotropic drug use was high (59\% and $62 \%$ in the donepezil and placebo groups, respectively). ${ }^{43}$ Neuropsychiatric Inventory-NH total scores were improved for both donepezil-treated patients and those who received placebo from 4 weeks until study end point at 6 months (Table 2). No significant difference was observed between treatment groups for total Neuropsychiatric Inventory scores. Individual item analysis showed that donepezil treatment significantly reduced agitation/aggression compared with placebo $(p=0.04)$. The second, more recent, trial specifically assessed the efficacy of donepezil in patients with severe Alzheimer's disease (MMSE scores of 1-10). ${ }^{57}$ As in the earlier nursing home study, concomitant psychotropic drug use was very common (> $80 \%$ of total study population). At study end point, total Neuropsychiatric Inventory scores were improved for both donepezil-treated and placebo-treated patients (Table 2). Again, no significant difference was observed between the donepezil and placebo treatment groups for total Neuropsychiatric Inventory scores.

Although rivastigmine has not been studied in a prospective, placebo-controlled trial in nursing home patients, a 52-week open-label study examined behavioral symptoms using the Neuropsychiatric Inventory-NH scale as the primary outcome measure. ${ }^{55,65}$ Nursing home residents with an MMSE score of 6-15 inclusive were enrolled; $77 \%$ had at least one behavioral symptom at baseline, and all were taking concomitant drugs for one or more comorbidities. After 26 weeks of rivastigmine treatment, $46 \%$ of patients showed a $30 \%$ or greater reduction in Neuropsychiatric Inventory-NH total score, and significant improvements were seen in 9 of the 12 individual Neuropsychiatric Inventory-NH domains $(p \leq 0.03) .{ }^{65}$ After 52 weeks, $45 \%$ of patients showed a $30 \%$ or greater reduction in Neuropsychiatric Inventory-NH total score, and 10 of the 12 individual Neuropsychiatric Inventory-NH domains were significantly improved over baseline. ${ }^{55}$ However, it should be noted that due to the open-label design of this study, ${ }^{55,65}$ caution must be used in drawing efficacy conclusions, especially since behavioral improvements were seen for both active drug and placebo in the donepezil nursing home studies. ${ }^{43,57}$

The apparent lack of a significant treatment difference between cholinesterase inhibitors and placebo in the nursing home studies contrasts with the significant behavioral benefits over placebo in community-dwelling patients with mild-to-moderate or moderate-to-severe Alzheimer's disease (Table 2). Suggested explanations for this lack of treatment effect include the high rate of concomitant psychotropic drug use in the nursing home patients (approximately 60\% to > 80\%), which may account for the behavioral improvements seen in the placebo groups. Indeed, in the study of donepezil for moderate-to-severe Alzheimer's disease ${ }^{47}$ which showed significant benefits of donepezil over placebo for problem behaviors, only $36-45 \%$ of the patients used psychotropic agents at some point during the study. Alternatively, it has been suggested that there is an inherent difference between studying Alzheimer's disease-related behavior in patients residing in different settings and, consequently, a differential sensitivity of the Neuropsychiatric Inventory in these settings. In a recent review, the authors noted that studies of cholinesterase inhibitors in nursing home patients have yielded mixed results and suggested that the efficacy measures for community-dwelling patients may not be appropriate for measuring outcomes in nursing home patients. ${ }^{66}$ The authors suggested that outcomes such as decreased hospital admissions, prevented falls, reduced staff turnover, and reduced use of pharmacologic and/or physical restraints may be more useful measures of efficacy in this population. 


\section{Safety}

The adverse events reported most often for patients taking cholinesterase inhibitors are nausea, vomiting, and diarrhea. Other less common adverse events include weight loss, insomnia, abnormal dreams, muscle cramps, bradycardia, syncope, and fatigue. Clinical experience suggests that starting cholinesterase inhibitor treatment at a low dosage and titrating the dosage upward gradually, may decrease the frequency of adverse events. ${ }^{67}$

\section{Memantine}

Memantine, an N-methyl-D-aspartate receptor antagonist, received FDA approval for the treatment of moderate-to-severe Alzheimer's disease in 2003. Studies of memantine monotherapy have shown that it provides cognitive and functional benefits to patients in late-stage disease. ${ }^{60}$ The effect of memantine treatment on the behavioral symptoms of Alzheimer's disease have also been assessed.

In a study of memantine monotherapy for moderate-to-severe Alzheimer's disease, no statistically significant treatment difference was observed between patients treated with memantine and those receiving placebo. ${ }^{60}$ Both groups showed worsened behavioral symptoms compared with baseline after 7 months of treatment, although the worsening was markedly less pronounced with memantine (Table 2 ). In a 6-month study of memantine add-on treatment, patients with moderate-to-severe Alzheimer's disease receiving long-term donepezil therapy (mean 2.45 yrs) were randomly assigned to receive either donepezil plus placebo or donepezil plus memantine. ${ }^{59}$ At study end point, total Neuropsychiatric Inventory scores remained at baseline severity in patients who received addon memantine treatment, but increased from baseline in patients receiving donepezil alone (treatment difference $\mathrm{p}=0.002$; Table 2). In recent post hoc analyses from this trial, Neuropsychiatric Inventory domain scores for agitation/aggression, irritability/lability, and appetite or eating change were statistically significant in favor of memantine at end point $(\mathrm{p} \leq 0.045){ }^{68}$ Although not conclusive, these results suggest that combined treatment with a cholinesterase inhibitor and memantine may provide additional benefits over each agent alone in terms of treating the behavioral symptoms of Alzheimer's disease.

Despite not being specifically approved for mild-to-moderate Alzheimer's disease by the FDA, a trial of memantine for patients in these stages of the disease was performed. ${ }^{58}$ In this study, 403 patients with mild-to-moderate Alzheimer's disease (MMSE score 10-22 inclusive) were randomized to memantine monotherapy or placebo. At 24 weeks, a statistically significant difference was noted in total Neuropsychiatric Inventory score in favor of memantine $(\mathrm{p}=0.011$; Table 2$)$.

\section{Safety}

The adverse events reported most often for patients receiving memantine include dizziness, confusion, headache, and constipation. Most reported adverse events were mild to moderate in severity. ${ }^{60,69}$

\section{Other Pharmacologic Treatments}

Pharmacologic therapy for the more severe behavioral symptoms of dementia, such as delusions and hallucinations, has traditionally included the conventional and atypical antipsychotics. ${ }^{45}$ Recent reviews of studies including these agents noted that comparative data demonstrating the advantages and disadvantages of antipsychotic drugs in dementia are generally lacking. ${ }^{56,70}$ Effectiveness of these agents is also difficult to assess given the robust placebo responses in these patients. ${ }^{70}$ Adverse effects for conventional antipsychotics include neurologic, cardiovascular, anticholinergic, and weight gain effects. ${ }^{71}$ Specific neurologic adverse events, such as tardive dyskinesia and other gait disturbances, can increase the risk of falls and hip fracture in this frail population. ${ }^{72,73}$

A review of pharmacologic treatments for neuropsychiatric symptoms of dementia indicated that the atypical antipsychotics, olanzapine and risperidone, have the best evidence for efficacy, with minimal adverse effects at lower doses. ${ }^{56}$ However, most of the antipsychotic trials reviewed in that article studied efficacy in nursing home residents or hospitalized patients, and, when reported, baseline Neuropsychiatric Inventory-NH scores were much higher than those in the cholinesterase inhibitor or memantine studies (mean treatment group score range 32.6-44.2). ${ }^{74,75}$ This suggests that these agents may be particularly suited for more advanced behavioral problems associated with dementia. Of interest, recent findings from the Clinical Antipsychotic Trials of Intervention Effectiveness-Alzheimer's 
Disease (CATIE-AD) trial, specifically designed to assess the effectiveness of atypical antipsychotics in patients with Alzheimer's disease, showed that the benefits of these agents on behaviors such as psychosis, agitation, or aggression, were in most cases offset by adverse events. ${ }^{76}$ The authors concluded that physicians and patients and/or their caregivers need to fully consider the risk:benefit ratio with these agents in order to optimize patient care. In principle, the combination of a low-dose atypical antipsychotic and either a cholinesterase inhibitor or memantine might be beneficial for the treatment of behavioral symptoms in patients with Alzheimer's disease, but such combinations have not been systematically studied in placebocontrolled, prospective, double-blind, randomized trials.

Atypical antipsychotics have a more favorable adverse-effect profile than that of conventional agents, ${ }^{77}$ although there are conflicting reports of whether they have fewer extrapyramidal symptoms. ${ }^{78,79}$ In the CATIE-AD trial, extrapyramidal symptoms were more common among individuals receiving olanzapine (12\%) and risperidone $(12 \%)$ than in those receiving quetiapine (2\%) or placebo (1\%). ${ }^{76}$ However, other adverse effects limit the utility of these drugs because some of the atypical drugs have the potential to exacerbate the cognitive and functional symptoms of Alzheimer's disease because of their anticholinergic properties. ${ }^{23}$ In addition, risperidone, ${ }^{80}$ olanzapine, ${ }^{81}$ and aripiprazole ${ }^{82}$ have been shown to result in cerebrovascular adverse events in dementia trials, although the clinical results supporting this association were not obtained from studies designed to prospectively assess the cerebrovascular effects of these agents. ${ }^{83}$ Results from a recent meta-analysis indicated no significant difference in the risk of ischemic stroke among patients with dementia treated with conventional or atypical antipsychotics. ${ }^{84}$

Recently, the FDA determined that the treatment of behavioral disorders in elderly patients with dementia with atypical (second generation) antipsychotic drugs is associated with increased mortality. ${ }^{85}$ Because of these findings, the FDA asked the manufacturers of these drugs to include a black-box warning in their labeling that describes this risk and notes that these drugs are not approved for this indication. Boxed warnings are now included in the prescribing information for these atypical agents. ${ }^{85}$ The findings of the FDA are supported by data from a recent meta-analysis of 15 randomized controlled trials, which showed that atypical antipsychotic drugs may be associated with increased mortality compared with placebo. ${ }^{86}$ Of interest, results of another recent study indicate that conventional antipsychotic drugs are at least as likely as atypical agents to cause death in elderly patients with dementia, and that conventional antipsychotics should not be used to replace agents discontinued due to the FDA warning. ${ }^{87}$

As depression is a common symptom for patients in the early stages of dementia, antidepressant therapies have been used to treat patients with Alzheimer's disease. The older tricyclic antidepressants have proved to be of limited value for patients with dementia because of the anticholinergic adverse effects associated with their use. Selective serotonin reuptake inhibitors have been shown to be better tolerated than tricyclic antidepressants, and they help alleviate the depressive symptoms of patients with dementia, ${ }^{45}$ although no clear benefits on neuropsychiatric symptoms have been reported in controlled studies. ${ }^{56}$

Another common behavioral symptom of Alzheimer's disease is agitation. In patients with Alzheimer's disease, agitation may be reduced by treatment with mood-stabilizing agents. Some studies of carbamazepine indicate significant benefits for agitation, whereas others studies are less conclusive regarding the effects of carbamazepine on behavioral symptoms. ${ }^{56,67,88-91}$ Likewise, studies of divalproex sodium have yielded mixed efficacy results. ${ }^{56,67,92-94}$

Benzodiazepines may be used for the treatment of agitation in some patients. In a double-blind, randomized, placebo-controlled trial investigating the efficacy of the atypical antipsychotic olanzapine and the benzodiazepine lorazepam in treating dementia-associated agitation, both drugs showed significant improvement over placebo on agitation scales at 2 hours, which was maintained at 24 hours for olanzapine only. ${ }^{95}$ Sedation, adverse events, and laboratory analyses were not significantly different from those of the placebo group for either drug. Generally, only a modest response to benzodiazepines is seen in patients with Alzheimer's disease, and other disadvantages include sedation, tolerance, risk of falls, and dependence. Therefore, they may be most useful in managing occasional nonpsychotic agitation or anxiety, but they are not recommended for the long-term management of behavioral symptoms. ${ }^{56,96}$ 


\section{Discussion}

The behavioral symptoms of Alzheimer's disease tend to increase in prevalence and severity as the disease progresses and frequently precipitate nursing home placement. Recognizing and treating behavioral symptoms early with nonpharmacologic and/or pharmacologic treatments can slow symptom progression. Appropriate treatment of Alzheimer's disease can also reduce the distress to patients and caregivers and may delay placement of a patient in a residential care facility or nursing home. ${ }^{97,98}$

Prospective, randomized, placebo-controlled trials have shown that the cholinesterase inhibitors, donepezil and galantamine, can provide behavioral benefits for patients with mild-to-moderate Alzheimer's disease. In addition, donepezil treatment has been shown to improve behavioral symptoms in patients with moderate-to-severe Alzheimer's disease. Memantine treatment as an add-on to long-term donepezil therapy has also been shown to benefit patients with moderate-to-severe Alzheimer's disease, and memantine monotherapy has provided behavioral benefits in patients with mild-to-moderate Alzheimer's disease. In contrast, results from randomized, placebocontrolled studies of cholinesterase inhibitors in nursing home patients are less convincing, mainly due to the robust placebo response and the uncertain sensitivity of the Neuropsychiatric Inventory as a measure of behavioral problems in these patients.

When considering the effects of cholinesterase inhibitors and memantine on behavior, the benefits, although significant, are often highlighted as generally being small. ${ }^{56,64}$ As shown in Table 2, this is often the case. However, even when the reported changes in Neuropsychiatric Inventory scores seem numerically low in relation to the overall scale range, the percentage change from baseline score can occasionally show more promise. For example, in one study, among patients with mild-to-moderate Alzheimer's disease, those treated with donepezil showed a 2.9-point reduction in Neuropsychiatric Inventory score, which seems negligible in relation to the overall scale range of $0-120 .{ }^{49}$ Nevertheless, when considered in relation to the change from baseline scores, the donepeziltreated patients showed a $20 \%$ improvement in behavioral symptoms, whereas placebo-treated patients showed a $22 \%$ worsening of behavioral symptoms over the same time period. When viewed in this manner, the possible benefits of these agents are somewhat clearer.

In addition to cholinesterase inhibitors and memantine, other pharmacologic agents, such as antipsychotics, antidepressants, mood-stabilizing agents, and benzodiazepines, can assist with problem behaviors. Indeed, many of these agents are effectively used to treat the behavioral symptoms of Alzheimer's disease, particularly in patients with severe behavioral problems. However, none of these agents is approved by the FDA for the specific treatment of the behavioral symptoms of Alzheimer's disease. Moreover, use of these agents may be limited by uncertain efficacy, poor safety profiles, and/or potential anticholinergic effects, and many are not recommended for long-term management of behavioral problems.

\section{Conclusion}

Nonpharmacologic strategies remain the cornerstone of the management of Alzheimer's disease-related behavioral symptoms. However, when pharmacologic intervention is deemed necessary for problem behaviors, it is important that physicians, pharmacists, and nurses recognize the possible beneficial effects of cholinesterase inhibitors, either alone or with memantine as appropriate for the stage of disease, and consider these agents as a first-line option for early pharmacologic treatment of the behavioral symptoms of Alzheimer's disease.

\section{References}

1. Galasko D. An integrated approach to the management of Alzheimer's disease: assessing cognition, function and behaviour. Eur J Neurol 1998;5(suppl 4):S9-17.

2. Hebert LE, Scherr PA, Bienias JL, Bennett DA, Evans DA. Alzheimer disease in the US population: prevalence estimates using the 2000 census. Arch Neurol 2003;60:1119-22.

3. Evans DA, Funkenstein HH, Albert MS, et al. Prevalence of Alzheimer's disease in a community population of older persons: higher than previously reported. JAMA 1989;262: 2551-6.

4. Krauss NA, Altman BM. Research findings no. 5: characteristics of nursing home residents-1996. Agency for Healthcare Research and Quality. Available from www.meps. ahrq.gov/mepsweb/data_files/publications/rf5/rf5.pdf. Accessed September 15, 2006.

5. Jost BC, Grossberg GT. The evolution of psychiatric symptoms in Alzheimer's disease: a natural history study. J Am Geriatr Soc 1996;44:1078-81

6. Mega MS, Cummings JL, Fiorello T, Gornbein J. The spectrum of behavioral changes in Alzheimer's disease. Neurology 1996;46:130-5.

7. Levy ML, Cummings JL, Kahn-Rose R. Neuropsychiatric symptoms and cholinergic therapy for Alzheimer's disease. Gerontology 1999;45(suppl 1):15-22.

8. Aggarwal N, Vass AA, Minardi HA, Ward R, Garfield C, Cybyk B. People with dementia and their relatives: personal 
experiences of Alzheimer's and of the provision of care. J Psychiatr Ment Health Nurs 2003;10:187-97.

9. Steele C, Rovner B, Chase GA, Folstein M. Psychiatric symptoms and nursing home placement of patients with Alzheimer's disease. Am J Psychiatry 1990;147:1049-51.

10. Coen RF, Swanwick GR, O'Boyle CA, Coakley D. Behaviour disturbance and other predictors of caregiver burden in Alzheimer's disease. Int J Geriatr Psychiatry 1997;12:331-6.

11. Moore MJ, Zhu CW, Clipp EC. Informal costs of dementia care: estimates from the national longitudinal caregiver study. J Gerontol B Psychol Sci Soc Sci 2001;56B:S219-28.

12. Alzheimer's Association. Behavioral and psychiatric Alzheimer's symptoms. Alzheimer's Association fact sheet. Available from www.alz.org/Resources/FactSheets/fs_ behavioralandpsychiatric.pdf. Accessed September 15, 2006.

13. Aronstein Z, Olsen R, Schulman E. The nursing assistants use of recreational interventions for behavioral management of residents with Alzheimer's disease. Am J Alzheimers Dis 1996;11:26-31

14. Churchill M, Safaoui J, McCabe BW, Baun MM. Using a therapy dog to alleviate the agitation and desocialization of people with Alzheimer's disease. J Psychosoc Nurs Ment Health Serv 1999:37:16-22.

15. Cohen-Mansfield J, Werner P. Management of verbally disruptive behaviors in nursing home residents. J Gerontol A Biol Sci Med Sci 1997;52A:M369-77.

16. Cohen-Mansfield J. Nonpharmacologic interventions for inappropriate behaviors in dementia: a review, summary, and critique. Am J Geriatr Psychiatry 2001;9:361-81.

17. Desai AK, Grossberg GT. Recognition and management of behavioral disturbances in dementia. Prim Care Companion J Clin Psychiatry 2001;3:93-109.

18. Gerdner L. An individualized music intervention for agitation. J Am Psychiatr Nurses Assoc 1997;3:177-84

19. Holmberg SK. Evaluation of a clinical intervention for wanderers on a geriatric nursing unit. Arch Psychiatr Nurs 1997;11:21-8.

20. Ballard CG, O'Brien JT, Reichelt K, Perry EK. Aromatherapy as a safe and effective treatment for the management of agitation in severe dementia: the results of a double-blind, placebo-controlled trial with melissa. J Clin Psychiatry 2002;63:553-8.

21. Mishima K, Okawa M, Hishikawa Y, Hozumi S, Hori, H, Takahashi K. Morning bright light therapy for sleep and behavior disorders in elderly patients with dementia. Acta Psychiatr Scand 1994:89:1-7.

22. Namazi KH, Gwinnup PB, Zadorozny CA. A low intensity exercise/movement program for patients with Alzheimer's disease: the TEMP-AD protocol. J Aging Phys Act 1994:2:80-92.

23. Osterweil D. Alzheimer's disease in the long-term care setting: management of behavioral disturbances with cholinesterase inhibitors. Ann Long Term Care 2004;12:18-24.

24. Rogers JC, Holm MB, Burgio LD, et al. Improving morning care routines of nursing home residents with dementia. J Am Geriatr Soc 1999;47:1049-57.

25. Sobel BP. Bingo vs physical intervention in stimulating shortterm cognition in Alzheimer's disease patients. Am J Alzheimers Dis Other Demen 2001;16:115-20.

26. Sultzer DL, Cummings JL. Alzheimer's disease. In: Rakel R, Conn H, eds. Current therapy: latest approved methods of treatment for the practicing physician. Philadelphia: WB Saunders; 1993:838-40.

27. Ray WA, Taylor JA, Meador KG, et al. Reducing antipsychotic drug use in nursing homes: a controlled trial of provider education. Arch Intern Med 1993;153:713-21.

28. Shinosaki K, Nishikawa T, Takeda M. Neurobiological basis of behavioral and psychological symptoms in dementia of the Alzheimer type. Psychiatry Clin Neurosci 2000;54:611-20.

29. Holroyd S, Shepherd ML, Downs JH III. Occipital atrophy is associated with visual hallucinations in Alzheimer's disease. J Neuropsychiatry Clin Neurosci 2000;12:25-8.

30. Craig AH, Cummings JL, Fairbanks L, et al. Cerebral blood flow correlates of apathy in Alzheimer disease. Arch Neurol 1996;53:1116-20.

31. Nakano S, Yamashita F, Matsuda H, Kodama C, Yamada T. Relationship between delusions and regional cerebral blood flow in Alzheimer's disease. Dement Geriatr Cogn Disord 2006;21:16-21.

32. Lanctot KL, Herrmann N, Nadkarni NK, Leibovitch FS, Caldwell CB, Black SE. Medial temporal hypoperfusion and aggression in Alzheimer disease. Arch Neurol 2004; 61:1731-7.

33. Mega MS, Dinov ID, Lee L, et al. Orbital and dorsolateral frontal perfusion defect associated with behavioral response to cholinesterase inhibitor therapy in Alzheimer's disease. J Neuropsychiatry Clin Neurosci 2000;12:209-18.

34. Benoit M, Clairet S, Koulibaly PM, Darcourt J, Robert PH. Brain perfusion correlates of the apathy inventory dimensions of Alzheimer's disease. Int J Geriatr Psychiatry 2004;19:864-9.

35. Cummings JL, Kaufer D. Neuropsychiatric aspects of Alzheimer's disease: the cholinergic hypothesis revisited. Neurology 1996;47:876-83

36. Staff RT, Gemmell HG, Shanks MF, Murray AD, Venneri A. Changes in the rCBF images of patients with Alzheimer's disease receiving donepezil therapy. Nucl Med Commun 2000;21:37-41

37. Nakano S, Asada T, Matsuda H, Uno M, Takasaki M. Donepezil hydrochloride preserves regional cerebral blood flow in patients with Alzheimer's disease. J Nucl Med 2001;42: 1441-5

38. Venneri A, Shanks MF, Staff RT, et al. Cerebral blood flow and cognitive responses to rivastigmine treatment in Alzheimer's disease. Neuroreport 2002;13:83-7.

39. Sultzer DL, Mahler ME, Mandelkern MA, et al. The relationship between psychiatric symptoms and regional cortical metabolism in Alzheimer's disease. J Neuropsychiatry Clin Neurosci 1995;7:476-84

40. Sultzer DL, Brown CV, Mandelkern MA, et al. Delusional thoughts and regional frontal/temporal cortex metabolism in Alzheimer's disease. Am J Psychiatry 2003;160:341-9.

41. Cummings JL, Mega M, Gray K, Rosenberg-Thompson S, Carusi DA, Gornbein J. The Neuropsychiatric Inventory: comprehensive assessment of psychopathology in dementia. Neurology 1994:44:2308-14.

42. Wood S, Cummings JL, Hsu MA, et al. The use of the neuropsychiatric inventory in nursing home residents: characterization and measurement. Am J Geriatr Psychiatry 2000;8:75-83

43. Tariot PN, Cummings JL, Katz IR, et al. A randomized, double-blind, placebo-controlled study of the efficacy and safety of donepezil in patients with Alzheimer's disease in the nursing home setting. J Am Geriatr Soc 2001;49:1590-9.

44. Kaduszkiewicz H, Zimmermann T, Beck-Bornholdt HP, van den Bussche H. Cholinesterase inhibitors for patients with Alzheimer's disease: systematic review of randomised clinical trials. BMJ 2005;331:321-7.

45. Doody RS, Stevens JC, Beck C, et al. Practice parameter: management of dementia (an evidence-based review): report of the quality standards subcommittee of the American Academy of Neurology. Neurology 2001;56:1154-66.

46. Burns A, Rossor M, Hecker J, et al. The effects of donepezil in Alzheimer's disease: results from a multinational trial. Dement Geriatr Cogn Disord 1999;10:237-44.

47. Feldman H, Gauthier S, Hecker J, Vellas B, Subbiah P, Whalen E. A 24-week, randomized, double-blind study of donepezil in moderate to severe Alzheimer's disease. Neurology 2001;57:613-20

48. Corey-Bloom J, Anand R, Veach J. A randomized trial evaluating the efficacy and safety of ENA 713 (rivastigmine tartrate), a new acetylcholinesterase inhibitor, in patients with mild to moderately severe Alzheimer's disease. Int J Geriatr Psychopharmacol 1998;1:55-65.

49. Holmes C, Wilkinson D, Dean C, et al. The efficacy of donepezil in the treatment of neuropsychiatric symptoms in Alzheimer disease. Neurology 2004;63:214-19. 
50. Mohs RC, Doody RS, Morris JC, et al. A 1-year, placebocontrolled preservation of function survival study of donepezil in AD patients. Neurology 2001;57:481-8.

51. Raskind MA, Peskind ER, Wessel T, Yuan W. Galantamine in AD: a 6-month randomized, placebo-controlled trial with a 6month extension. Neurology 2000;54:2261-8.

52. Rosler M, Anand R, Cicin-Sain A, et al. Efficacy and safety of rivastigmine in patients with Alzheimer's disease: international randomised controlled trial. BMJ 1999;318:633-8.

53. Tariot PN, Solomon PR, Morris JC, Kershaw P, Lilienfeld S, Ding C. A 5-month, randomized, placebo-controlled trial of galantamine in AD. Neurology 2000;54:2269-76.

54. Rockwood K, Mintzer J, Truyen L, Wessel T, Wilkinson D. Effects of a flexible galantamine dose in Alzheimer's disease: a randomised, controlled trial. J Neurol Neurosurg Psychiatry 2001;71:589-95.

55. Aupperle PM, Koumaras B, Chen M, Rabinowicz A, Mirski D. Long-term effects of rivastigmine treatment on neuropsychiatric and behavioral disturbances in nursing home residents with moderate to severe Alzheimer's disease: results of a 52-week open-label study. Curr Med Res Opin 2004;20: 1605-12.

56. Sink KM, Holden KF, Yaffe K. Pharmacological treatment of neuropsychiatric symptoms of dementia: a review of the evidence. JAMA 2005;293:596-608.

57. Winblad B, Kilander L, Eriksson S, et al. Donepezil in patients with severe Alzheimer's disease: double-blind, parallel-group, placebo-controlled study. Lancet 2006;367:1057-65.

58. Peskind ER, Potkin SG, Pomara N, et al. Memantine treatment in mild to moderate Alzheimer disease: a 24-week randomized, controlled trial. Am J Geriatr Psychiatry 2006;14:704-15.

59. Tariot PN, Farlow MR, Grossberg GT, Graham SM, McDonald S, Gergel I. Memantine treatment in patients with moderate to severe Alzheimer disease already receiving donepezil: a randomized controlled trial. JAMA 2004;291:317-24

60. Reisberg B, Doody R, Stoffler A, Schmitt F, Ferris S, Mobius HJ. Memantine in moderate-to-severe Alzheimer's disease. N Engl J Med 2003;348:1333-41.

61. Wilcock G, Howe I, Coles H, et al. A long-term comparison of galantamine and donepezil in the treatment of Alzheimer's disease. Drugs Aging 2003;20:777-89.

62. Courtney C, Farrell D, Gray R, et al. Long-term donepezil treatment in 565 patients with Alzheimer's disease (AD2000): randomised double-blind trial. Lancet 2004;363:2105-15.

63. Birks J. Cholinesterase inhibitors for Alzheimer's disease. [Cochrane review]. In: The Cochrane Library, Issue 1, 2006 [online]. Available from www.mrw.interscience.wiley.com/ cochrane/clsysrev/articles/CD005593/pdf_fs.html. Accessed September 15, 2006

64. Trinh NH, Hoblyn J, Mohanty S, Yaffe K. Efficacy of cholinesterase inhibitors in the treatment of neuropsychiatric symptoms and functional impairment in Alzheimer disease: a meta-analysis. JAMA 2003;289:210-16.

65. Cummings JL, Koumaras B, Chen M, Mirski D. Effects of rivastigmine treatment on the neuropsychiatric and behavioral disturbances of nursing home residents with moderate to severe probable Alzheimer's disease: a 26-week, multicenter, openlabel study. Am J Geriatr Pharmacother 2005;3:137-48.

66. Khang P, Weintraub N, Espinoza RT. The use, benefits, and costs of cholinesterase inhibitors for Alzheimer's dementia in long-term care: are the data relevant and available? J Am Med Dir Assoc 2004:5:249-55.

67. Cummings JL. Alzheimer's disease. N Engl J Med 2004;351: $56-67$.

68. Cummings J, Schneider E, Tariot PN, et al. Behavioral effects of memantine in Alzheimer disease patients receiving donepezil treatment. Neurology 2006;67:57-63.

69. Forest Laboratories. Namenda (memantine) package insert. St. Louis, MO; 2005.

70. Daiello L, Beier M, Hoffmann V, Kennedy JS. Pharmacotherapy of behavioral and psychological symptoms of dementia: a review of atypical antipsychotics. Consult Pharm 2003;18:138-57.
71. Schneider LS. Pharmacologic management of psychosis in dementia. J Clin Psychiatry. 1999;60(suppl 8):54-60.

72. Ray WA, Griffin MR, Schaffner W, Baugh DK, Melton LJ III Psychotropic drug use and the risk of hip fracture. N Engl J Med 1987;316:363-9.

73. Tinetti ME, Williams TF, Mayewski R. Fall risk index for elderly patients based on number of chronic disabilities. Am J Med 1986;80:429-34.

74. Street JS, Clark WS, Gannon KS, et al. Olanzapine treatment of psychotic and behavioral symptoms in patients with Alzheimer disease in nursing care facilities: a double-blind, randomized, placebo-controlled trial. The HGEU study group. Arch Gen Psychiatry 2000;57:968-76.

75. De Deyn PP, Carrasco MM, Deberdt W, et al. Olanzapine versus placebo in the treatment of psychosis with or without associated behavioral disturbances in patients with Alzheimer's disease. Int J Geriatr Psychiatry 2004;19:115-26.

76. Schneider LS, Tariot PN, Dagerman KS, et al. Effectiveness of atypical antipsychotic drugs in patients with Alzheimer's disease. N Engl J Med 2006;355:1525-38.

77. Cohen GD. Alzheimer's disease: managing behavioral problems in patients with progressive dementia. Geriatrics 2002;57:53-4.

78. Miller $\mathrm{CH}$, Mohr F, Umbricht D, Woerner M, Fleischhacker WW, Lieberman JA. The prevalence of acute extrapyramidal signs and symptoms in patients treated with clozapine, risperidone, and conventional antipsychotics. J Clin Psychiatry 1998;59:69-75.

79. Rochon PA, Stukel TA, Sykora K, et al. Atypical antipsychotics and parkinsonism. Arch Intern Med 2005;165:1882-8.

80. Janssen Pharmaceutica. Risperdal (risperidone) package insert. Titusville, NJ; 2005.

81. Eli Lilly. Zyprexa (olanzapine) package insert. Indianapolis, IN; 2005.

82. Bristol-Myers Squibb and Otsuka America Pharmaceutical. Abilify (aripiprazole) package insert. Princeton, NJ, and Rockville, MD; 2005.

83. Smith DA, Beier MT. Association between risperidone treatment and cerebrovascular adverse events: examining the evidence and postulating hypotheses for an underlying mechanism. J Am Med Dir Assoc 2004;5:129-32.

84. Gill SS, Rochon PA, Herrmann N, et al. Atypical antipsychotic drugs and risk of ischaemic stroke: population based retrospective cohort study. BMJ 2005;330:445-8.

85. Food and Drug Administration, Center for Drug Evaluation and Research. Deaths with antipsychotics in elderly patients with behavioral disturbances. Available from www.fda.gov/ cder/drug/advisory/antipsychotics.htm. Accessed September 15, 2006.

86. Schneider LS, Dagerman KS, Insel P. Risk of death with atypical antipsychotic drug treatment for dementia: metaanalysis of randomized placebo-controlled trials. JAMA 2004;294:1934-43.

87. Wang PS, Schneeweiss S, Avorn J, et al. Risk of death in elderly users of conventional vs atypical antipsychotic medications. N Engl J Med 2005;353:2335-41.

88. Gleason RP, Schneider LS. Carbamazepine treatment of agitation in Alzheimer's outpatients refractory to neuroleptics. J Clin Psychiatry 1990;51:115-18.

89. Lemke MR. Effect of carbamazepine on agitation in Alzheimer's inpatients refractory to neuroleptics. J Clin Psychiatry 1995;56:354-7.

90. Tariot PN, Erb R, Podgorski CA, et al. Efficacy and tolerability of carbamazepine for agitation and aggression in dementia. Am J Psychiatry 1998;155:54-61.

91. Olin JT, Fox LS, Pawluczyk S, Taggart NA, Schneider LS. A pilot randomized trial of carbamazepine for behavioral symptoms in treatment-resistant outpatients with Alzheimer disease. Am J Geriatr Psychiatry 2001;9:400-5.

92. Tariot PN, Schneider LS, Mintzer JE, et al. Safety and tolerability of divalproex sodium in the treatment of signs and symptoms of mania in elderly patients with dementia: results of a double-blind, placebo-controlled trial. Curr Ther Res Clin Exp 2001;62:51-67. 
93. Porsteinsson AP, Tariot PN, Erb R, et al. Placebo-controlled study of divalproex sodium for agitation in dementia. Am J Geriatr Psychiatry 2001;9:58-66.

94. Porsteinsson AP, Tariot PN, Jakimovich LJ, et al. Valproate therapy for agitation in dementia: open-label extension of a double-blind trial. Am J Geriatr Psychiatry 2003;11:434-40.

95. Meehan KM, Wang H, David SR, et al. Comparison of rapidly acting intramuscular olanzapine, lorazepam, and placebo: a double-blind, randomized study in acutely agitated patients with dementia. Neuropsychopharmacology 2002;26:494-504.

96. Alexopoulos GS, Jeste DV, Chung H, Carpenter D, Ross R,
Docherty JP. The expert consensus guideline series: treatment of dementia and its behavioural disturbances. Postgrad Med (special report) January 2005.

97. Lopez OL, Becker JT, Wisniewski S, Saxton J, Kaufer DI, DeKosky ST. Cholinesterase inhibitor treatment alters the natural history of Alzheimer's disease. J Neurol Neurosurg Psychiatry 2002;72:310-14.

98. Geldmacher DS, Provenzano G, McRae T, Mastey V, Leni JR. Donepezil is associated with delayed nursing home placement in patients with Alzheimer's disease. J Am Geriatr Soc 2003;51:937-44. 